\title{
In utero exposure to heat stress during late gestation has prolonged effects on the activity patterns and growth of dairy calves
}

\author{
J. Laporta, ${ }^{1}$ T. F. Fabris, A. L. Skibiel, J. L. Powell, M. J. Hayen, K. Horvath, E. K. Miller-Cushon, \\ and G. E. Dahl \\ Department of Animal Sciences, University of Florida, Gainesville 32611
}

\begin{abstract}
Exposure to heat stress during late gestation exerts negative carryover effects on the postnatal performance of the calf. In this study, we evaluated the health, growth, and activity patterns of calves born to cows exposed to heat stress (HT, provided only shade, $\mathrm{n}=$ 31 ) or cooling (CL, fans, soakers, and shade, $\mathrm{n}=29$ ) during late gestation ( $\sim 46 \mathrm{~d}$, maternal dry period). Calves' body weight, rectal temperature, suckling reflex, and movement scores were recorded at birth, and calves were fed $6.6 \mathrm{~L}$ of maternal colostrum in 2 meals. Blood samples were collected at birth (before feeding), $24 \mathrm{~h}$ after birth, and at d 10 and 28 of age. Calves were housed in individual pens, fed pasteurized milk $(6 \mathrm{~L} / \mathrm{d})$, and had ad libitum access to grain and water until weaning ( $49 \mathrm{~d})$. Activity was assessed during the first week of life (wk 1), at weaning (wk 7), and in the first week postweaning (wk 8) using electronic data loggers. Health and body weight were monitored weekly. At birth, calves born to CL cows were heavier (41.9 vs. $39.1 \pm 0.8 \mathrm{~kg}$ ), their temperature was lower (38.9 vs. $39.3 \pm 0.08^{\circ} \mathrm{C}$ ), and they were more efficient at absorbing IgG than HT calves. Suckling reflex and movement score at birth were not different between groups, but calves born to CL cows spent more time $(50 \mathrm{~min} / \mathrm{d})$ standing in the first week of life as a result of longer standing bouts. In wk 7 and 8 , calves born to CL cows had less frequent standing bouts than HT heifers, but CL heifers maintained greater total daily standing time (36 min/d) due to longer (7 min/bout) standing bouts. All calves were healthy, but HT heifers tended to have higher (looser) fecal scores on d 10. Heifers born from CL cows gained $0.2 \mathrm{~kg} / \mathrm{d}$ more from birth to weaning, weighed $4 \mathrm{~kg}$ more at weaning, and had greater concentrations of IGF-1 than HT calves, particularly
\end{abstract}

Received September 12, 2016.

Accepted December 3, 2016.

${ }^{1}$ Corresponding author: jlaporta@ufl.edu on d 28. In utero heat stress during late gestation had immediate and prolonged effects on passive immunity, growth, and activity patterns in dairy calves.

Key words: heat stress, immunity, activity, dairy calf

\section{INTRODUCTION}

Dairy cows exposed to heat stress during lactation have reduced feed intake, impaired systemic physiology, and decreased milk production (Collier et al., 2006; Baumgard and Rhoads, 2013). Exposing dairy cows to heat stress during the dry period, between 2 consecutive lactations, compromises mammary gland development prepartum (Tao et al., 2011), decreasing milk production in the subsequent lactation (do Amaral et al., 2009, 2011). Prenatal stressors, such as the plane of nutrition, environmental stress, and social stress, can also lead to impaired fetal development and compromised postnatal performance (Wu et al., 2006; Merlot et al., 2008; Reynolds et al., 2010). However, the effect of maternal heat stress on developing offspring during late gestation and the adverse short- and long-term consequences for their future performance, growth, and immunity are less studied and understood.

The in utero exposure of calves to heat stress has been shown to induce fetal growth retardation by decreasing uterine blood flow (Oakes et al., 1976), placental weight (Alexander and Williams, 1971), and the birth weight of the offspring (Collier et al., 1982; Tao et al., 2012a). Calves born to cows under heat stress during the dry period are lighter at birth and have lower passive immunity than calves born to cooled cows (do Amaral et al., 2011; Tao et al. 2012a; Monteiro et al., 2014). In addition to the in utero effects, recent studies have shown that heat stress also exerts carryover effects on the postnatal performance of the offspring during the preweaning period, including immune function (Tao et al., 2012a; Monteiro et al., 2014; Strong et al., 2015) and metabolic adaptations (Tao et al., 2014; Monteiro et al., 2016b). Understanding behavior is also a valuable tool when assessing animal welfare, and activity patterns are influenced by a range of factors, 
such as bedding material and comfort (Sutherland et al., 2014), and health (Proudfoot et al., 2014). Activity is also influenced by temperature: both calves and cows spend less time lying down in hot summer temperatures (Overton et al., 2002; Tripon et al., 2014). However, studies exploring the effect of in utero heat stress on the activity of dairy calves are lacking.

In this study, we set out to evaluate the physiological, behavioral, and immune responses induced by in utero heat stress during late gestation (i.e., the maternal dry period), and the effect on the growth and health of the calf before weaning. We hypothesized that in utero exposure to heat stress would negatively affect calf responsiveness at birth and patterns of activity, and would compromise postnatal health and growth compared with calves born to cows that were provided with active cooling during the dry period.

\section{MATERIALS AND METHODS}

\section{Animals and Experimental Design}

Maternal Treatments and Management. We conducted a trial at the Dairy and Calf Units of University of Florida (Hague) during the summer and fall of 2015 (June to December). Treatments and animal handling were approved by the University of Florida Institutional Animal Care and Use Committee. Pregnant multiparous Holstein cows were dried off approximately $46 \mathrm{~d}$ before expected calving and randomly assigned to 1 of 2 treatments: heat stress $(\mathbf{H T}, \mathrm{n}=31)$ or cooling $(\mathbf{C L}, \mathrm{n}=29)$. Groups were balanced by parity (average $2.8 \pm 0.86$ ) and mature equivalent milk production from their previous lactation. Cow sample size per treatment was calculated based on milk production data (27.7 vs. $34.0 \mathrm{~kg} / \mathrm{d}$, respectively, $\mathrm{SD}=6.2 \mathrm{~kg} / \mathrm{d}$ ) for the heat stressed or cooled dry cows in the next lactation (Tao et al., 2012b), using a level of significance of 0.05 and $85 \%$ power. All cows were housed in the same freestall barn in 2 pens during the dry period. In the CL pen, cows were actively cooled using fans (J\&D Manufacturing, Eau Claire, WI) and soakers (Rain Bird Manufacturing, Glendale, CA) over the feed bunks, whereas in the HT pen cows were provided with only shade (roof with open sides). When the ambient temperature exceeded $21.1^{\circ} \mathrm{C}$, fans automatically turned on, and soakers were activated for $1.5 \mathrm{~min}$ at $5 \mathrm{~min}$ intervals. The treatments assigned to calves, HT or CL in utero, reflected the treatments assigned to their dams during the dry period (late gestation). All cows were fed a common close-up TMR throughout the dry period $(15.4 \% \mathrm{CP}$, $34.5 \% \mathrm{NDF}, 0.62 \% \mathrm{Ca}, 0.37 \% \mathrm{P}, 036 \% \mathrm{Na}, 0.4 \% \mathrm{Cl}$, $0.3 \% \mathrm{Mg}, 0.2 \% \mathrm{~S})$.
The air temperature and relative humidity of each pen in the barn were recorded every 15 min using Hobo Pro series temperature probes (Onset Computer Corp., Pocasset, MA). The temperature-humidity index (THI) was calculated based on the equation reported by Dikmen et al. (2008). The average THI during the experimental period was similar for the HT and CL pens, and was $\geq 72$ (average 77.6 and 77.9 for CL and $\mathrm{HT}$, respectively) during the day and night for the entire period, but cows in the CL group had access to fans and soakers to ameliorate the adverse effects of the THI. Rectal temperature was measured twice daily (0730 and 1430 h) using a GLA M700 digital thermometer (GLA Agricultural Electronics, San Luis Obispo, $\mathrm{CA}$ ), and respiration rate was monitored 3 times per week (1400 h, by counting the flank movements for 1 min) for all cows during the dry period to confirm the heat burden.

Calf Management. A total of 60 calves were born to cows exposed to HT ( $\mathrm{n}=15$ heifers, $\mathrm{n}=16$ bulls) and CL ( $\mathrm{n}=15$ heifers, $\mathrm{n}=14$ bulls) environmental conditions during the entire dry period $(47.6 \pm 1.5$ and $43.9 \pm 1.4 \mathrm{~d}$ for CL and HT cows, respectively). All calves were born between July 14 and October 6, 2015. Measurements at birth were performed for heifers and bull calves, but only heifers $(\mathrm{n}=13$ born to CL dry cows, $\mathrm{n}=9$ born to HT dry cows) were kept and followed until weaning. At birth, all calves were separated from their dams and had their navel dipped with $2 \%$ iodine to prevent infection. Day of birth was considered study d 0 . Within $4 \mathrm{~h}$ of calving, dams were milked in the parlor using a portable milking unit to collect colostrum according to dairy unit standard operating procedures. A colostrum sample was collected and stored at $-20^{\circ} \mathrm{C}$. Calves were fed $6.6 \mathrm{~L}$ of fresh colostrum from their dam in 2 separate meals $(3.8 \mathrm{~L}$ within $4 \mathrm{~h}$ and $2.8 \mathrm{~L}$ within $12 \mathrm{~h}$ after birth) by bottle or by esophageal feeder when needed ( 5 calves were tube-fed due to lack of interest in drinking the colostrum offered). Depending on colostrum availability, some calves were fed frozen colostrum collected from a different dam, as long as it belonged to the same treatment group. Eight heifer calves, 6 from the HT group and 2 from the CL group, were removed from the experiment because they received insufficient colostrum. After $1 \mathrm{~d}$ of age, heifer calves were transported to the calf unit, housed in individual pens, and provided with $6 \mathrm{~L} / \mathrm{d}$ of pasteurized milk for $21 \mathrm{~d}$ and $8 \mathrm{~L} / \mathrm{d}$ after that until weaning at $49 \mathrm{~d}$. All calves had ad libitum access to grain and water from birth to weaning. Grain intake was not recorded. Calves were weaned by reducing their milk allotment to $3 \mathrm{~L} / \mathrm{d}$ for $1 \mathrm{wk}$. All calves were exposed to the same management thereafter. All vac- 
cinations were based on dairy unit standard operating procedures for calves.

\section{Sample Collection and Measurements at Birth}

Shortly after birth and before the first colostrum feeding, calves' BW and rectal temperature were recorded, and scores were assigned for suckling reflex (0 to $3 ; 0$ $=$ no suckling response, $3=$ strong suckling response; Murray et al., 2015) and movement [0 to 3; $0=$ not able to stand when prompted (gently tapped on back), 3 = stands promptly or already standing; adapted from Murray et al., 2015]. Before colostrum consumption, blood was collected from the jugular vein using 2 Vacutainer tubes $(10 \mathrm{~mL}$, Becton Dickinson, Franklin Lakes, NJ) containing clot activator gel (placed at room temperature for $\sim 30 \mathrm{~min}$ ) or sodium-heparin anticoagulant (placed immediately on ice before processing). Serum and plasma were separated by centrifugation at $3,000 \times$ $g$ for 20 min at $4^{\circ} \mathrm{C}$, aliquoted, and stored frozen $\left(-20^{\circ} \mathrm{C}\right)$ until the time of assay. Additional blood samples were collected at $24 \mathrm{~h}$ after colostrum consumption and on d 10 and 28 after calving, and serum and plasma were processed following the same procedures for laboratory analysis of IgG, IGF-1, and cortisol.

\section{Colostrum and Serum IgG}

Colostrum quality was assessed immediately after collection using a digital refractometer (MA871; Milwaukee Instruments Inc., Rocky Mount, NC), and a 50 $\mathrm{mL}$ sample was stored at $-20^{\circ} \mathrm{C}$. We estimated the apparent efficiency of absorption (AEA, \%) indirectly by measuring the IgG content in first-milking colostrum and calf serum at $24 \mathrm{~h}$ after colostrum ingestion using the single radial immunodiffusion test (Bovine IgG Test Kit; Triple J Farms, Bellingham, WA) described previously by Monteiro et al. (2014) for calves. Calculations were performed using a formula described by Quigley and Drewry (1998): [plasma IgG $(\mathrm{g} / \mathrm{L}) \times$ birth weight $(\mathrm{kg}) \times$ plasma volume $(\mathrm{L}) / \operatorname{IgG}$ fed $(\mathrm{g})] \times 100$.

\section{Growth and Health Parameters}

We obtained the hip height and BW of the heifer calves on d 10 and 28, and at weaning. We also calculated ADG at the same time points. Heifer activity was monitored during the first week of life (wk 1; d 1 to 8), at weaning (wk 7; d 43 to 49), and in the first week after weaning (wk 8; d 50 to 56) using electronic data loggers (Hobo Pendant G Data Logger; Onset Computer Corp., Pocasset, MA) attached to the calf's left rear leg (as validated for use in calves by Bonk et al., 2013). Stand- ing activity was recorded as total daily standing time, daily standing bout frequency, daily average standing bout duration, and hourly standing time. Heifer health was assessed on $\mathrm{d} 10$ and 28 and at weaning, using fecal score $(0$ to $3 ; 0=$ normal, $1=$ semi-formed and pasty, 2 $=$ loose, but stays on top of bedding, $3=$ watery, sifts through bedding), and the presence of nasal or ocular discharges (0 to $3 ; 0=$ normal, $3=$ heavy discharge), according to McGuirk (2008). Rectal temperature was recorded on d 10, 28, and 49 .

\section{Blood Parameters}

We determined the plasma concentration of IGF-1 using a chemiluminescent enzyme immunoassay according to the manufacturer's instructions (Immulite 1000; Siemens Medical Solutions Diagnostics, Los Angeles, CA) and a monoclonal murine anti-IGF-1 antibody (Cat\# LKGF1; Siemens Medical Solutions Diagnostics). The assay was validated for bovine serum by Brandão et al. (2016). Controls were analyzed in duplicate with coefficient of variation $<5 \%$. Serum cortisol concentration was determined using a chemiluminescent enzyme immunometric assay in a commercial kit coated with a polyclonal rabbit anti-cortisol antibody (Cat\# LKC01; Siemens Medical Solutions Diagnostics) and the Immulite 1000 (Siemens Medical Solutions Diagnostics) according to the manufacturer's instructions. The intra-assay coefficient of variation was $7.4 \%$, and those for low and high control sera were $<5 \%$.

\section{Statistical Analysis}

Data were analyzed using SAS v. 9.4 (SAS Institute, Cary, NC). We analyzed measurements at birth using a generalized linear mixed model with calf sex and treatment (HT and CL) as a fixed effect, and calf ID as a random effect. We analyzed measurements over time using a general linear model including the fixed effects of treatment, day (repeated measure), and their interaction. We used the first order autoregressive covariance structure AR (1) as the covariate structure. We analyzed responsiveness data (suckling reflex and movement score) and health scores using the Wilcoxon signed rank test. Analyses of daily standing activity were performed separately by time period (wk 1, wk 7 , or wk 8) in a general linear model, treating day as a repeated measure. To assess standing activity during the day, we averaged the hourly totals of time spent standing by calf and week across observation days within each week. We analyzed data separately by week, treating hour as a repeated measure. Gestation length and the respiration rate and rectal temperature of the dams 
A

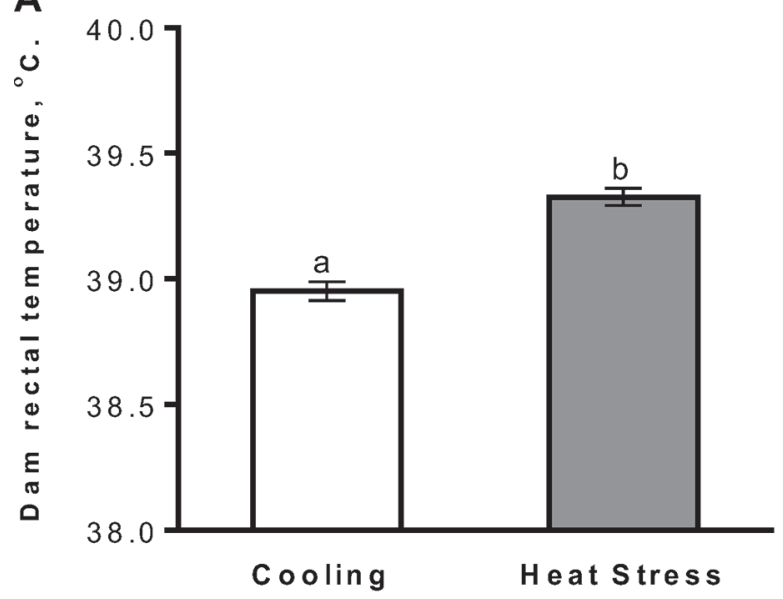

C

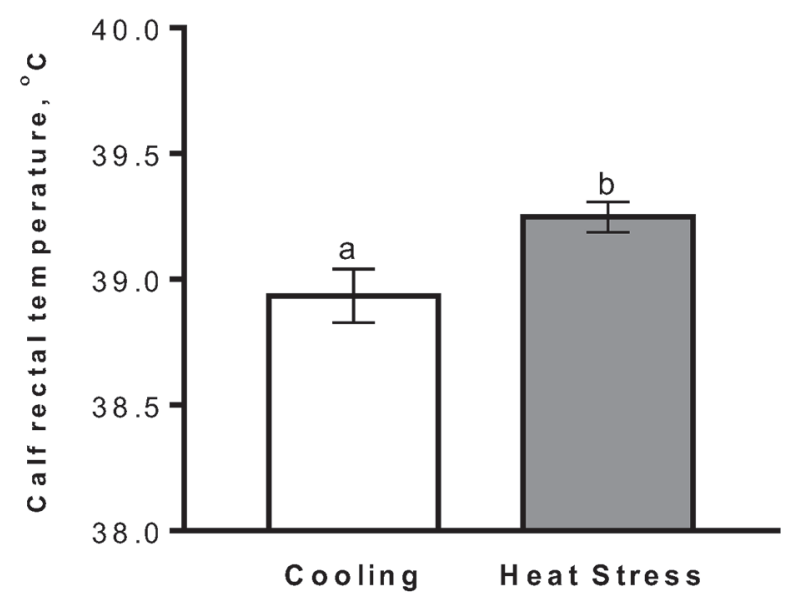

B

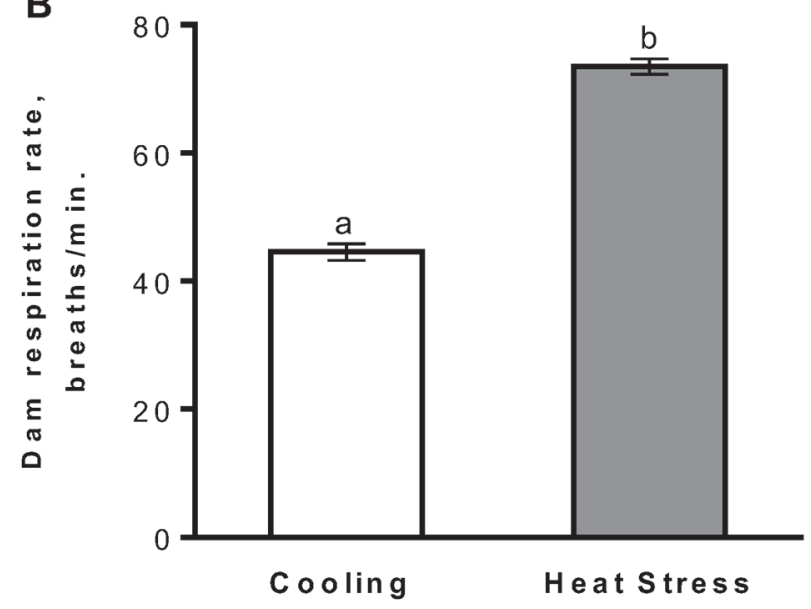

D

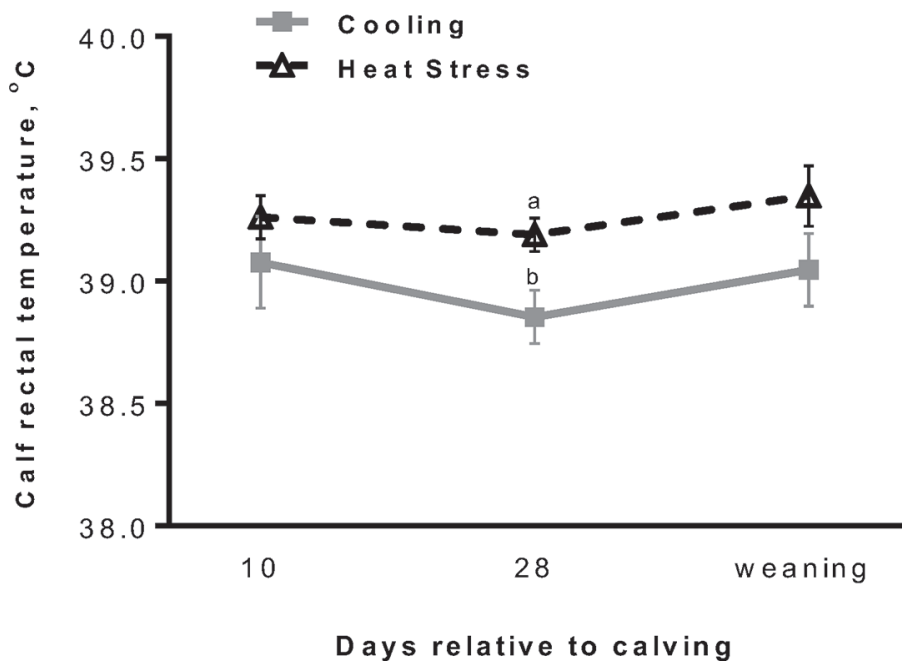

Figure 1. (A) Rectal temperature and (B) respiration rate of Holstein cows that were actively cooled (CL, fans and soakers over the feed bunks, $\mathrm{n}=31$ ) or heat stressed (HT, provided with only shade, $\mathrm{n}=27)$ during the dry period of approximately 46 d. Rectal temperature at $(\mathrm{C})$ birth and (D) postcalving (d 10, d 28) and at weaning (d 49) of calves born to CL ( $=13$ ) or HT (n = 9) cows during late gestation (maternal dry period). Data are presented as mean \pm SEM, and different letters indicate statistical difference $(P<0.05)$.

were analyzed using a generalized linear mixed model with treatment, day, and their interaction as fixed effects and cow within treatment as a random effect. All values reported are LSM \pm SEM. We performed normality and outlier tests for all variables. Differences with $P \leq 0.05$ were considered statistically significant, and differences between $0.05 \leq P \leq 0.10$ were tending toward significance.

\section{RESULTS AND DISCUSSION}

\section{Indicators of Heat Stress}

We confirmed the effectiveness of the heat stress treatment applied to the cows during the dry period.
The pens for both CL and HT cows had similar THI during the dry period, indicating that all cows were exposed to a similar degree of heat stress, and that the cooling system effectively reduced CL cows' rectal temperature ( 39.0 vs. $39.3 \pm 0.03^{\circ} \mathrm{C}$ for $\mathrm{CL}$ and $\mathrm{HT}$ cows, respectively, $P<0.001)$ and respiration rate (44.5 vs. $73.5 \pm 1.3$ breaths/min for CL and HT cows, respectively, $P<0.001$ ) compared with HT cows (Figure 1A, B). Gestation length was approximately $4 \mathrm{~d}$ longer for CL cows than for HT cows (275.2 vs. 278.9 $\pm 1.0 \mathrm{~d}$ for HT and CL cows, respectively, $P<0.01$ ). At birth, the rectal temperature of calves born to HT cows was higher $\left(39.3\right.$ vs. $38.9 \pm 0.08^{\circ} \mathrm{C}$ for $\mathrm{HT}$ and $\mathrm{CL}$ calves, respectively, $P<0.01$; Figure 1C) than for those born to CL cows. Rectal temperature in the preweaning 
period was higher for heifers born to HT cows than for those born to $\mathrm{CL}$ cows $\left(39.3\right.$ vs. $38.9 \pm 0.06^{\circ} \mathrm{C}, P<$ 0.01; Figure 1D).

\section{Growth and Health Parameters}

At birth, calves born to HT cows were lighter (39.0 vs. $41.9 \pm 0.8 \mathrm{~kg}$ for HT and CL calves, respectively, $P=0.02$; Figure 2A) than calves born to CL cows. Calves' ADG was similar from birth to d 10 and d 28, and averaged $1.36 \pm 0.15 \mathrm{~kg} / \mathrm{d}$; however, from birth to weaning, heifers born from CL cows gained $0.2 \mathrm{~kg}$ more per day than heifers born to HT cows $(P=0.05$, Figure $2 \mathrm{C}$ ). Body weights at weaning tended to be higher in calves born to CL cows $(78.9$ vs. $75.3 \pm 1.7 \mathrm{~kg}$ for CL and HT calves, respectively, $P=0.07$; Figure $2 \mathrm{~B}$ ), but after weaning, ADG was not different between groups, and heifers gained an average of $1.07 \pm 0.02 \mathrm{~kg} / \mathrm{d}$. Hip height was not different between groups at any time point evaluated and averaged $32.6,33.7$, and $35.9 \pm 0.5$ $\mathrm{cm}$ for $\mathrm{d} 10, \mathrm{~d} 28$, and weaning, respectively. Concentrations of IGF-1 increased over time $(P<0.001)$ for both treatment groups, and we detected a tendency $(P$ $=0.08)$ toward a treatment $\times$ day interaction. Heifers born from CL cows tended to have higher concentrations of IGF-1 than those born from HT cows, particularly on d 28 (130.0 vs. $82.3 \pm 12.0 \mathrm{ng} / \mathrm{mL}$, respectively, $P=$ 0.01). Cortisol concentration decreased approximately 5 -fold from birth to d $10(7.7$ vs. $1.4 \pm 0.65 \mu \mathrm{g} / \mathrm{dL}$, respectively, $P<0.001$ ), but we observed no overall maternal treatment effect or interaction. We observed a few instances of minor nasal discharge (in 1 calf born to a CL cow and 3 calves born to HT cows) and no cases of ocular discharge; those data were not analyzed statistically. However, heifers born to HT cows tended to have higher (looser) fecal scores on d 10 (1.41 vs. $0.72 \pm 0.9, P=0.08)$. Fecal scores were similar between treatments on d 28 and 49.

Our results confirmed previous findings that maternal heat stress during late pregnancy shortens gestation length and decreases calf birth weight and growth (Tao et al., 2012a; Monteiro et al., 2016b). Short-term effects on the physiology and immune function of calves gestated under conditions of heat stress have also been demonstrated (Tao et al., 2012b, 2014; Monteiro et al., 2014). This study was designed to evaluate preweaning growth and activity patterns, as well as components of passive immunity, in calves born to cows that were heat stressed or cooled in utero during late gestation. Although the THI in the hot and cooled pens was similar, rectal temperature and respiration rate were higher in HT cows, and the rectal temperature of their offspring was also higher at birth. Although all calves were maintained under identical conditions after birth, rectal temperature remained elevated throughout the preweaning period in HT calves relative to CL calves, suggesting carryover effects of in utero heat stress on calf thermoregulatory capacity throughout the preweaning period. Subtle thermal differences in utero over a relatively short period can affect whole-animal bioenergetics postnatally. Similarly, in utero heat stressed piglets, regardless of the time of exposure during gestation, maintained a higher core body temperature than pigs that were gestated under thermoneutral environmental conditions (Johnson et al., 2015a). That same group of researchers has also shown that in utero heat stressed piglets had impaired growth and tissue accretion in the postnatal period (Johnson et al., 2015b). Similarly, calves born to heat stressed dams had altered responses to acute heat stress at maturity (Ahmed et al., 2015),
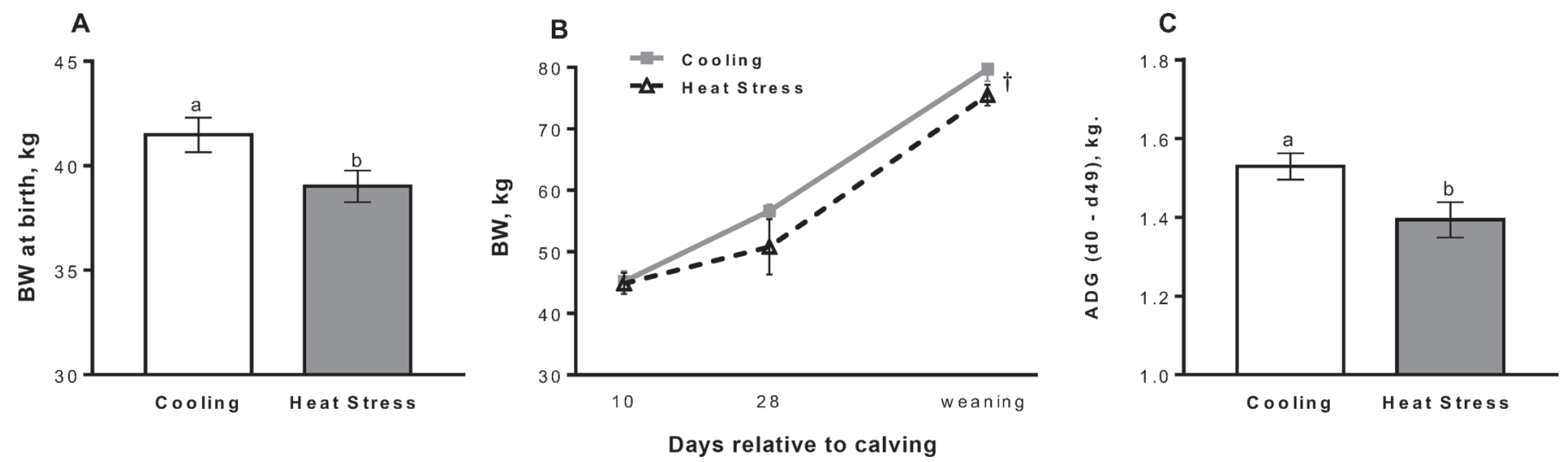

Figure 2. (A) Body weight at birth; (B) BW postcalving (d 10, d 28) and at weaning (d 49); and (C) ADG from birth (d 0) to weaning (d 49) from calves born to cooled (fans and soakers over the feed bunks, $n=13$ ) or heat stressed (provided with only shade, $n=9$ ) cows during late gestation (dry period, approximately $46 \mathrm{~d}$ ). Data are presented as mean $\pm \mathrm{SEM}$, different letters indicate statistical difference $(P<0.05)$, and $\dagger$ indicates a tendency $(P \leq 0.10)$. 

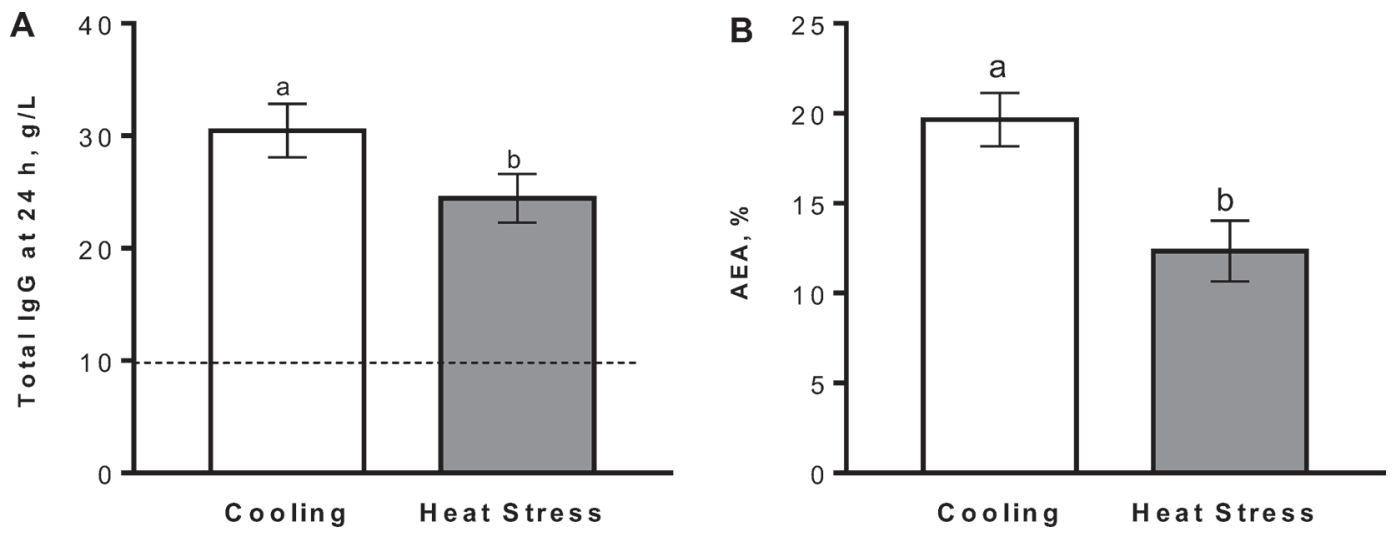

Figure 3. (A) Concentration of IgG in serum at $24 \mathrm{~h}$ after birth, and (B) apparent efficiency of absorption (AEA, \%) calculated based on the Quigley and Drewry (1998) equation from calves born to cooled (fans and soakers over the feed bunks, $\mathrm{n}=13$ ) or heat stressed (provided with only shade, $\mathrm{n}=9$ ) cows during late gestation (dry period, approximately $46 \mathrm{~d}$ ). The dotted line indicates the IgG threshold of $10 \mathrm{~g} / \mathrm{L}$. Data are presented as mean \pm SEM, and different letters indicate statistical difference $(P<0.05)$.

suggesting that in utero adaptations to heat stress may confer improved ability to respond to heat load later in life. Specifically, when calves that had been gestated under heat stress were challenged with acute heat stress as adults, they did not express the same elevation in rectal temperature as their herd mates from cooled dams. Therefore, in utero heat stress during late gestation can permanently affect postnatal phenotypes, altering the future thermoregulatory response and growth of offspring independent of the postnatal environment.

\section{Passive Immunity}

We estimated the apparent efficiency of immunoglobulin absorption by measuring IgG content in dams' colostrum and in calf serum at $24 \mathrm{~h}$ (after colostrum ingestion). Dam colostrum IgG concentration was higher for HT than for CL cows (126 vs. $99.6 \pm 6.4$ $\mathrm{g} / \mathrm{L}$, respectively, $P<0.001)$. Plasma concentrations of IgG at $24 \mathrm{~h}$ were higher for CL than for HT calves (30.5 vs. $24.4 \pm 2.2 \mathrm{~g} / \mathrm{L}, P=0.05$; Figure $3 \mathrm{~A}$ ), but were not different on d 10 and $28(P>0.03)$. The apparent efficiency of IgG absorption was less in calves born to HT cows than in those born to CL cows (12.3 vs. 20\%, respectively, $P<0.01$; Figure $3 \mathrm{~B}$ ).

Similar effects of maternal heat stress on calf serum IgG and AEA have been described in studies that used comparable experimental models (Tao et al., 2012a; Monteiro et al., 2014). The higher IgG concentration of colostrum from HT cows could be attributed to differences in colostrum volume between treatment groups. It is well known that heat stressed cows produce less milk throughout lactation (Tao and Dahl, 2013), but we did not quantify colostrum yield in our study. The specific cause of the lower AEA of IgG in HT calves is not yet known and warrants further investigation. We know that heat stress during gestation can result in intrauterine growth restriction due to impaired placental function, reduced blood flow through the feto-placental unit, and truncated gestation length (Tao and Dahl, 2013). In our study, intrauterine growth restriction was evidenced by lower birth weight and shorter gestation length in HT calves. Thus, it is possible that in utero heat stress during late gestation impairs development of the fetal small intestine, resulting in reduced surface area for postnatal absorption. Recent evidence (Ahmed et al., 2015) suggests that impaired passive immune transfer due to prenatal heat stress is a consequence of decreased enterocyte turnover in the small intestine during the first days of the calf's life. The lower birth weight observed in HT calves, together with the compromised passive immunity, might have led to compromised growth and looser fecal scores.

\section{Activity Patterns and Behavior During Early Life and Weaning Periods}

At birth, suckling reflex $(2.2 \pm 0.72$ vs. $1.9 \pm 0.83)$ and movement scores $(2.5 \pm 0.52$ vs. $2.36 \pm 0.66, P>$ 0.69) were similar for calves born to CL and HT cows, respectively. However, in utero heat stress during late gestation had immediate and prolonged effects on calf activity. Heifer calves born from CL cows spent more time standing in the first week of life (Table 1) as a result of longer standing bouts, whereas standing bout frequency was similar between treatments. In wk 7 and 8 , before and after weaning, CL heifers had longer but less frequent standing bouts, and greater standing time overall compared with HT heifers (Table 1). Daily patterns of standing activity were not subject to treatment 
Table 1. Standing activity of calves, born to cooled (CL, $\mathrm{n}=13$ ) or heat-stressed $(\mathrm{HT}, \mathrm{n}=9$ ) cows during late gestation (dry period of $\sim 46$ d), immediately after birth (d 1-8), during weaning (d 43-49) and postweaning (d 50-56) ${ }^{1}$

\begin{tabular}{|c|c|c|c|c|c|c|}
\hline \multirow[b]{2}{*}{ Item } & \multicolumn{2}{|c|}{ Treatment } & \multirow[b]{2}{*}{ SEM } & \multicolumn{3}{|c|}{$P$-value } \\
\hline & $\mathrm{HT}$ & CL & & Treatment & Day $^{2}$ & Treatment $\times$ day \\
\hline \multicolumn{7}{|l|}{ Wk 1 (d 1-8) } \\
\hline Standing time, $\min / \mathrm{d}$ & 254.34 & 303.57 & 9.6 & $<0.001$ & 0.07 & 0.85 \\
\hline Standing bout duration, $\min /$ bout & 12.20 & 14.18 & 0.55 & 0.005 & 0.001 & 0.29 \\
\hline Standing bout frequency, bouts/d & 21.89 & 24.72 & 1.35 & 0.10 & 0.45 & 0.89 \\
\hline \multicolumn{7}{|l|}{ Weaning (d 43-49) } \\
\hline Standing bout frequency, bouts/d & 17.75 & 15.70 & 0.61 & 0.01 & 0.56 & 0.75 \\
\hline \multicolumn{7}{|l|}{ Postweaning (d 50-56) } \\
\hline Standing time, $\min / \mathrm{d}$ & 414.24 & 452.51 & 8.1 & $<0.001$ & $<0.001$ & 0.54 \\
\hline Standing bout duration, $\min /$ bout & 24.85 & 32.61 & 1.09 & $<0.001$ & 0.003 & 0.09 \\
\hline Standing bout frequency, bouts/d & 17.60 & 15.08 & 0.46 & $<0.001$ & 0.95 & 0.28 \\
\hline
\end{tabular}

${ }^{1}$ Data are presented as mean \pm SEM; $P<0.05$ indicates statistical difference.

${ }^{2}$ Day within week.

$\times$ hour interactions during any week analyzed $(P>$ 0.35 ), indicating that patterns of standing during the day were similar between CL and HT heifers.

Consistent with analysis of daily standing behavior, daily standing patterns were affected by treatment in all weeks evaluated $(P<0.018)$, reflecting increased standing over the course of the day in CL heifers. Daily feeding patterns differed over the hours of the day $(P<$ 0.001 , Figure 4 ), with peaks in standing activity corresponding to the delivery of milk ( $0600 \mathrm{~h}$ and $1800 \mathrm{~h}$ ) in wk 1 (Figure 4A), and arrival of farm staff and external cues of other calves receiving milk in wk 8 (postweaning, Figure 4B). In general, lying time in young calves is encouraged through management factors, such as softer bedding (Sutherland et al., 2014), and is considered an indicator of comfort. Further, Hänninen et al. (2005) described a positive correlation between lying time and ADG in preweaned calves, suggesting that adequate rest is important for calf performance. However, the causes and consequences of individual variations in lying time among calves that are managed in the same environment have not been well explored.

Given the negative effects of maternal heat stress on calf birth weight, differences in the activity of calves in the present study could be indicative of other deficiencies, such as potential effects of prenatal exposure to heat stress on muscular development, but we encourage further work to assess this possibility. Interestingly, standing and lying in cows is influenced by environmental factors, with lying time decreasing under conditions of heat stress (Cook et al., 2007), likely in an attempt by the cow to facilitate evaporative cooling. Similarly, calves spend more time lying in winter than in summer (Tripon et al., 2014). It could be speculated that differences in perception of thermal comfort may have influenced some activity patterns in the present study, considering that calves born to HT cows spent less time standing and also tended to have higher rectal temperatures. Limitations of this study included the small sample size per treatment, the infrequent evaluation of clinical health parameters, the lack of THI information for the calf pens, and the wide range of the calving season (preweaning periods occurred between mid-July and early December).

Experiments should be conducted that follow the performance of the heifers in subsequent lactations after being exposed to heat stress in late gestation to determine whether the observed effects in early life continue through lactation. Similarly, future research is needed on fetal responses to maternal heat stress to understand the underlying causes and the potential long-term effects this might have.

\section{CONCLUSIONS}

This study provides evidence that in utero heat stress during late gestation has both immediate and prolonged effects on the passive immunity, growth, and activity patterns of dairy calves, and could contribute to postnatal thermoregulatory capacity. These observations might explain, in part, the impaired performance of heat stressed heifers postweaning, observed previously by Monteiro et al. (2016a). Understanding the negative consequences for the offspring of late-gestation environmental heat stress is crucial for the development of management practices aimed at enhancing the productivity, health, and well-being of dairy calves.

\section{ACKNOWLEDGMENTS}

We thank the staff and students at the University of Florida Dairy Research Unit. This project was sup- 

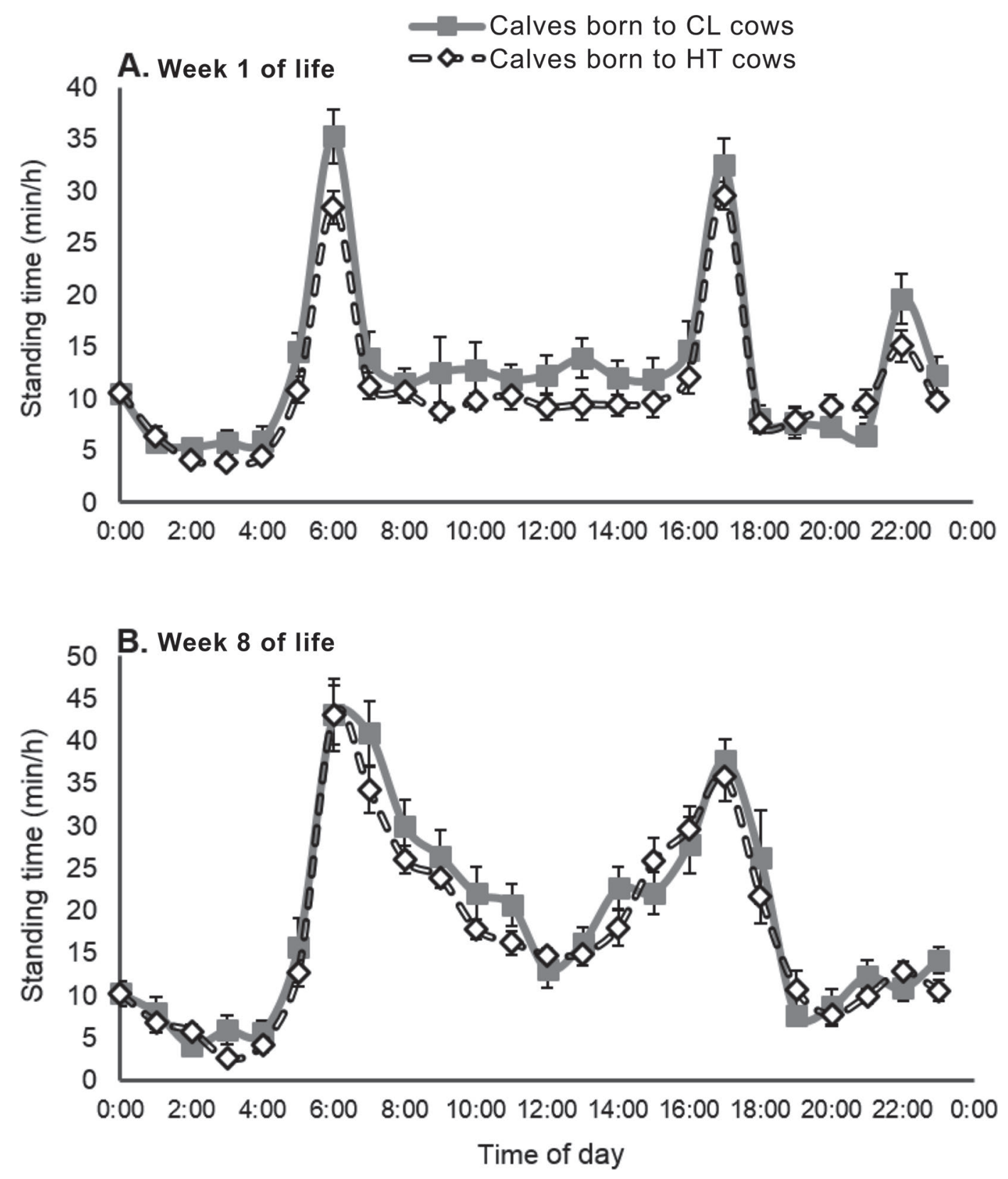

Figure 4. Daily standing activity during (A) the first week of life, and (B) week 8 of life, the first week postweaning of calves born to cows that were cooled (CL, fans and soakers over the feed bunks, $\mathrm{n}=13$ ) or heat stressed (HT, provided with only shade, $\mathrm{n}=9$ ) during late gestation (dry period approximately $46 \mathrm{~d}$ ). Daily standing activity was subject to treatment effects $(P<0.02)$ and hour effects $(P<0.001)$, but no treatment $\times$ week interaction in both weeks. Data are presented as mean \pm SEM.

ported through departmental funding (Department of Animal Sciences, University of Florida).

\section{REFERENCES}

Ahmed, B. M., U. Younas, T. O. Asar, S. Dikman, P. J. Hansen, and G. E. Dahl. 2015. Cows exposed to heat stress in utero exhibit improved thermal tolerance. J. Dairy Sci. 98(Suppl. 2):862. (Abstr.)

Ahmed, B. M. S., U. Younas, T. O. Asar, A. P. A. Monteiro, J. Hayen, S. Tao, and G. E. Dahl. 2016. Maternal heat stress reduces body and organ growth in calves: Relationship to immune tissue development. J. Dairy Sci. 99(Supp1.1):606. (Abstr.)

Alexander, G., and D. Williams. 1971. Heat stress and development of the conceptus in domestic sheep. J. Agric. Sci. 76:53-72.

Baumgard, L. H., and R. P. Rhoads Jr.. 2013. Effects of heat stress on postabsorptive metabolism and energetics. Annu. Rev. Anim. Biosci. 1:311-337.

Bonk, S., O. Burfeind, V. S. Suthar, and W. Heuwieser. 2013. Technical note: Evaluation of data loggers for measuring lying behavior in dairy calves. J. Dairy Sci. 96:3265-3271.

Brandão, P., R. F. Cooke, F. N. Corrá, M. B. Piccolo, R. Gennari, T. Leiva, and J. L. M. Vasconcelos. 2016. Physiologic, health, and 
production responses of dairy cows supplemented with an immunomodulatory feed ingredient during the transition period. J. Dairy Sci. 99:5562-5572.

Collier, R. J., G. E. Dahl, and M. J. VanBaale. 2006. Major advances associated with environmental effects on dairy cattle. J. Dairy Sci. 89:1244-1253.

Collier, R. J., S. G. Doelger, H. H. Head, W. W. Thatcher, and C. J. Wilcox. 1982. Effects of heat stress during pregnancy on maternal hormone concentrations, calf birth weight and postpartum milk yield of Holstein cows. J. Anim. Sci. 54:309-319.

Cook, N. B., R. L. Mentink, T. B. Bennet, and K. Burgi. 2007. The effect of heat stress and lameness on time budgets of lactating dairy cows. J. Dairy Sci. 90:1674-1682.

Dikmen, S., E. Alava, E. Pontes, J. M. Fear, B. Y. Dikmen, T. A. Olson, and P. J. Hansen. 2008. Differences in thermoregulatory ability between slick-haired and wild-type lactating Holstein cows in response to acute heat stress. J. Dairy Sci. 91:3395-3402.

do Amaral, B. C., E. E. Connor, S. Tao, J. Hayen, J. Bubolz, and G. E. Dahl. 2009. Heat-stress abatement during the dry period: Does cooling improve transition into lactation? J. Dairy Sci. 92:59885999 .

do Amaral, B. C., E. E. Connor, S. Tao, M. J. Hayen, J. W. Bubolz, and G. E. Dahl. 2011. Heat stress abatement during the dry period influences metabolic gene expression and improves immune status in the transition period of dairy cows. J. Dairy Sci. 94:86-96.

Hänninen, L., A. M. De Passillé, and J. Rushen. 2005. The effect of flooring type and social grouping on the rest and growth of dairy calves. Appl. Anim. Behav. Sci. 91:193-204.

Johnson, J. S., M. Abuajamieh, V. M. Sanz Fernandez, J. T. Seibert, S. K. Stoakes, A. F. Keating, J. W. Ross, J. T. Selsby, R. P. Rhoads, and L. H. Baumgard. 2015b. The impact of in utero heat stress and nutrient restriction on progeny body composition. J. Therm. Biol. 53:143-150.

Johnson, J. S., M. V. Sanz Fernandez, J. T. Seibert, J. W. Ross, M. C Lucy, T. J. Safranski, T. H. Elsasser, S. Kahl, R. P. Rhoads, and L. H. Baumgard. 2015a. In utero heat stress increases postnatal core body temperature in pigs. J. Anim. Sci. 93:4312-4322.

McGuirk, S. M. 2008. Disease management of dairy calves and heifers. Vet. Clin. North Am. Food. Anim. Pract. 24:139-153.

Merlot, E., D. Couret, and W. Otten. 2008. Prenatal stress, fetal imprinting and immunity. Brain Behav. Immun. 22:42-51.

Monteiro, A. P. A., J.-R. Guo, X.-S. Weng, B. M. Ahmed, M. J. Hayen, G. E. Dahl, J. K. Bernard, and S. Tao. 2016b. Effect of maternal heat stress during the dry period on growth and metabolism of calves. J. Dairy Sci. 99:3896-3907.

Monteiro, A. P. A., S. Tao, I. M. Thompson, and G. E. Dahl. 2014. Effect of heat stress during late gestation on immune function and growth performance of calves: Isolation of altered colostral and calf factors. J. Dairy Sci. 97:6426-6439.

Monteiro, A. P. A., S. Tao, I. M. T. Thompson, and G. E. Dahl. 2016a. In utero heat stress decreases calf survival and performance through the first lactation. J. Dairy Sci. 99:8443-8450.
Murray, C. F., D. B. Haley, T. F. Duffield, D. L. Pearl, S. M. Deelen and K. E. Leslie. 2015. A field study to evaluate the effects of meloxicam NSAID therapy and calving assistance on newborn calf vigor, improvement of health and growth in preweaned Holstein calves. Bovine Pract. 49:1-12.

Oakes, G. K., A. M. Walker, R. A. Ehrenkranz, R. C. Cefalo, and R. A. Chez. 1976. Uteroplacental blood flow during hyperthermia with and without respiratory alkalosis. J. Appl. Physiol. 41:197-201.

Overton, M. W., W. M. Sischo, G. D. Temple, and D. A. Moore. 2002 Using time-lapse video photography to assess dairy cattle lying behavior in a free-stall barn. J. Dairy Sci. 85:2407-2413.

Proudfoot, K. L., M. B. Jensen, D. M. Weary, and M. A. G. von Keyserlingk. 2014. Dairy cows seek isolation at calving and when ill. J. Dairy Sci. 97:2731-2739.

Quigley, J. D., III, and J. J. Drewry. 1998. Nutrient and immunity transfer from cow to calf pre- and postcalving. J. Dairy Sci. 81:2779-2790.

Reynolds, L. P., P. P. Borowicz, J. S. Caton, K. A. Vonnahme, J. S Luther, C. J. Hammer, K. R. Maddock Carlin, A. T. Grazul-Bilska, and D. A. Redmer. 2010. Developmental programming: The concept, large animal models, and the key role of uteroplacental vascular development. J. Anim. Sci. 88:E61-E72.

Strong, R. A., E. B. Silva, H. W. Cheng, and S. D. Eicher. 2015. Acute brief heat stress in late gestation alters neonatal calf innate immune functions. J. Dairy Sci. 98:7771-7783.

Sutherland, M. A., G. M. Worth, and M. Stewart. 2014. The effect of rearing substrate and space allowance on the behavior and physiology of dairy calves. J. Dairy Sci. 97:4455-4463.

Tao, S., J. W. Bubolz, B. C. do Amaral, I. M. Thompson, M. J. Hayen, S. E. Johnson, and G. E. Dahl. 2011. Effect of heat stress during the dry period on mammary gland development. J. Dairy Sci. 94:5976-5986.

Tao, S., and G. E. Dahl. 2013. Heat stress effects during late gestation on dry cows and their calves. J. Dairy Sci. 96:4079-4093.

Tao, S., A. P. Monteiro, I. M. Thompson, M. J. Hayen, and G. E. Dahl. 2012a. Effect of late gestation maternal heat stress on growth and immune function of dairy calves. J. Dairy Sci. 95:7128-7136.

Tao, S., A. P. A. Monteiro, M. J. Hayen, and G. E. Dahl. 2014. Short communication: Maternal heat stress during the dry period alters whole body insulin response of calves postnatally. J. Dairy Sci. 97:897-901.

Tao, S., I. M. Thompson, A. P. A. Monteiro, M. J. Hayen, L. J. Young, and G. E. Dahl. 2012b. Effect of cooling heat-stressed dairy cows during the dry period on insulin response. J. Dairy Sci. 95:50355046.

Tripon, I., L. T. Cziszter, and M. Bura. 2014. Effects of seasonal and climate variations on calves' thermal comfort and behavior. Int. J. Biometeorol. 58:1471-1478.

Wu, G., F. W. Bazer, J. M. Wallace, and T. E. Spencer. 2006. Board invited review: Intrauterine growth retardation: Implications for the animal sciences. J. Anim. Sci. 84:2316-2337. 